\title{
IMPLEMENTASI PROGRAM ADIWIYATA SEBAGAI STIMULUS SEKOLAH BERBASIS LINGKUNGAN SMA NEGERI 2 RAMBAH HILIR
}

\author{
Rindi Genesa Hatika ${ }^{1 *}$, Lusi Eka Afri ${ }^{2}$, Welven Aida ${ }^{3}$, Pariang Sonang Siregar ${ }^{4}$ \\ ${ }^{1}$ Pendidikan Fisika, Universitas Pasir Pengaraian, Indonesia \\ ${ }^{2}$ Pendidikan Matematika, Universitas Pasir Pengaraian, Indonesia \\ ${ }^{3}$ Pendidikan IPS, Universitas Pasir Pengaraian, Indonesia \\ ${ }^{4}$ Pendidikan Guru Sekolah Dasar, STKIP Rokania, Indonesia \\ ${ }^{1}$ rindigenesa@gmail.com, ${ }^{2}$ lusiekaafri13@gmail.com, ${ }^{3}$ welvenaida76@gmail.com, \\ ${ }^{4}$ pariangsonangsiregar@gmail.com
}

\begin{abstract}
ABSTRAK
Abstrak: Program Adiwiyata memberikan dampak yang baik dalam mewujudkan masyarakat peduli lingkungan.SMA Negeri 2 Rambah Hilir merupakan sekolah yang telah mencoba menerapkan program Adiwiyata di tingkat kabupaten, namun masih belum dapat diakui di tingkat provinsi dan nasional. Oleh karena itu, SMA Negeri 2 Rambah Hilir dipilih sebagai mitra agar dapat dilakukan stimulus sekolah berbasis lingkungan. Solusi yang ditawarkan kepada mitra yaitu SMA N 2 Rambah Hilir dalam mengatasi permasalahannya yaitu: (1) Melaksanakan program Adiwiyata sesuai dengan komponen-komponen Adiwiyata yaitu kebijakan berwawasan lingkungan, pelaksanaan kurikulum berbasis lingkungan, kegiatan lingkungan berbasis partisipatif dan pengelolaan sarana pendukung ramah lingkungan; (2) Memberikan pembinaan mengenai program Adiwiyata secara rutin kepada sekolah sehingga dapat secara mandiri menjadi sekolah Adiwiyata; (3) Pendampingan mitra dan pembinaan menuju sekolah Adiwiyata. Tim juga mendatangkan ahli lingkungan dari badan lingkungan hidup guna melakukan pembinaan tambahan sehingga mitra yaitu SMA N 2 Rambah Hilir dapat menyelesaikan masalah yang mereka hadapi; (4) Perancangan program unggulan Adiwiyata tambahan seperti Pelestarian TOGA, dan pembangunan Green house. Kegiatan implementasi Sekolah Adiwiyata ini, dapat menstimulasi SMA N 2 Rambah Hilir dalam semangat mengembangkan sekolah berbasis lingkungan sebesar $80 \%$. keberhasilan program ini terlihat dari antusiasnya mitra dalam mengembangkan sekolah Adiwiyata, pembangungan green house, pelestarian TOGA, Slogan lingkungan serta pemberian bibit dan tong sampah.
\end{abstract}

Kata Kunci: Adiwiyata; Sekolah Berbasis Lingkungan.

Abstract: The Adiwiyata Program has a good impact in realizing the community to care for the environment. SMA N 2 Rambah Hilir is a school that has tried to implement the Adiwiyata program at the district level, but it still cannot be recognized at the provincial and national levels. Therefore, SMA Negeri 2 Rambah Hilir was chosen as a partner in order to stimulate an environment-based school. The solutions offered to PKMS partners are SMA N 2 Rambah Hilir in overcoming their problems, namely: (1) Implementing Adiwiyata programs in accordance with Adiwiyata components, namely environmentally sound policies, implementation of environment based curriculum, environmentally based participatory activities and management of environmentally friendly supporting facilities; (2) Providing guidance on the Adiwiyata program routinely to schools so that they can independently become an Adiwiyata school; (3) Partner assistance and guidance to Adiwiyata School. The PKMS team also brought in environmental experts from the environmental agency to carry out additional coaching so that partners namely SMA N 2 Rambah Hilir could solve the problems they faced; (4) Designing additional superior Adiwiyata programs such as TOGA preservation and Green house development. The implementation of this Adiwiyata activity can stimulate SMA $\mathrm{N} 2$ Rambah Hilir in the spirit of developing an environment-based school by $80 \%$. The success of this program can be seen from the enthusiasm of partners in developing Adiwiyata schools, the construction of green houses, preservation of TOGA, environmental slogans and the provision of seeds and trash cans.

Keywords: Adiwiyata; School Based on Environment 


\section{A. LATAR BELAKANG}

Kondisi lingkungan global dewasa ini semakin memprihatinkan. Hal ini dipicu oleh ulah manusia yang mengekploitasi sumber daya alam dan lingkungan tanpa batas. Berkaitan dengan perilaku manusia terhadap kondisi sumber daya alam dan lingkungan yang cenderung tidak peduli, maka mengubah perilaku menjadi prioritas utama dalam mengatasi krisis lingkungan (Kasmawati, 2011), (Rotari, 2017). Kurangnya rasa peduli terhadap lingkungan sudah mendominasi di kalangan masyarakat Indonesia, tanpa memperdulikan akibat yang muncul di kemudian hari.

Masyarakat yang tinggal di kota-kota besar di seluruh Indonesia umumnya sudah terbiasa dengan masalah lingkungan misalnya, bertumpuknya sampah, pencemaran udara, kebisingan, air sungai yang keruh dan berbau, kekeringan, banjir, penurunan permukaan air tanah bahkan intrusi air laut (Selinaswati, 2019). Masalah lingkungan itu yang akan menjadi ancaman terutama bagi masyarakat di daerah yang kurang memperhatikan lingkungan. Kebiasaan dalam keseharian yang dihadapi terkait masalah lingkungan tersebut menyebabkan masyarakan menjadi tidak atau kurang peduli terhadap masalah lingkungan. Ketidakpedulian ini muncul akibat berbagai sebab, salah satu diantaranya adalah kurangnya pendidikan berbasis lingkungan (Paparang, 2017), (Insan, Nurdin, \& Darmawan, 2018).

Guna mengatasi permasalahan lingkungan, pemerintah telah menerbitkan Undang-Undang (UU) Nomor 32 Tahun 2009 pasal 65 ayat (2) tentang Perlindungan dan Pengelolaan Lingkungan Hidup, mengamanatkan bahwa setiap orang berhak mendapatkan pendidikan lingkungan hidup. Menimbang bahwa berdasarkan ketentuan pasal 63 huruf (w) Undang-Undang (UU) Nomor 32 Tahun 2009 tentang Perlindungan dan Pengelolaan Lingkungan Hidup, pemerintah dapat memberikan pendidikan, pelatihan, pembinaan dan penghargaan kepada orang atau lembaga yang berjasa di bidang lingkungan hidup. Artinya setiap individu, termasuk siswa juga diharapkan mampu turut serta mengambil peran dalam pengelolaan lingkungan (Arba, 2013).

Dasar-dasar pemikiran pada pasal 63 dan 65 sesuai dengan misi pendidikan yang tercantum pada Undang-undang Nomor 20 Tahun 2003 tentang Sistem Pendidikan Nasional, sebagai usaha sadar dan terencana untuk mewujudkan suasana belajar dan proses pembelajaran agar peserta didik sacara aktif mengembangkan potensi dirinya untuk memiliki kekuatan spiritual keagamaan, pengendalian diri, kepribadian, kecerdasan, akhlak mulia, serta keterampilan yang diperlukan dirinya, masyarakat, bangsa dan negara.

Pada Program Adiwiyata diharapkan dapat meningkatkan kepedulian masyarakat khususnya stakeholder pendidikan pada umumnya terhadap masalah lingkungan yang dihadapi, meningkatkan peran serta aktif masyarakat dalam menanggulangi masalah lingkungan hidup. Hal ini 
merupakan sasaran dalam jangka panjang dan dapat tercapai bila ada kesungguhan dalam pelaksanaan pembelajaran dan dukungan penuh dari pemerintah.

Selain itu pada tahun 2010 diterbitkan Surat Kesepakatan Bersama tentang Pendidikan Lingkungan Hidup nomor 03/MENLH/02/2010 dan nomor 01/II/KB/2010 [3] pasal kedua oleh 2 (dua) kementerian, yaitu: Kementerian Lingkungan Hidup dengan Kementerian Pendidikan Nasional. Ruang lingkup kesepakatan tentang Pendidikan Lingkungan Hidup ini meliputi: a) pengembangan pelaksanaan pendidikan untuk pembangunan berkelanjutan (Education for Substainable Development/ESD) termasuk pendidikan lingkungan hidup yang dilaksanakan pada semua jalur, jenjang dan jenis pendidikan sebagai wadah/sarana menciptakan perubahan pola piker, sikap, serta perilaku manusia yang berbudaya lingkungan hidup, b) koordinasi dan sinergi dalam penyusunan program lingkungan hidup jangka pendek, menengah, dan jangka panjang sebagai bagian dari ESD, c) revitalisasi penelitian dan pemngembangan dalam bidang perlindungan dan pengelolaan lingkungan hidup, d) memberikan penghargaan kepada individu, lembaga dan masyarakat yang peduli dan/atau berprestasi dalam bidang perlindungan dan pengelolaan lingkungan hidup, dan e) peningkatan kapasitas, komitmen dan peran serta masyarakat, pemangku kebijakan pendidikan pusat dan daerah, serta pendidik dan tenaga kependidikan untuk berperan aktif menjaga dan melestarikan fungsi lingkungan hidup.

Lingkungan sekolah bagi anak adalah sebagai ruang bermain dan belajar, peranan lingkungan sekolah ini bertindak sebagai pembelajaran nonformal ataupun formal. Dikatakan nonformal, siswa dapat belajar sendiri mengenai jenis vegetasi baik tanaman hias, sayur, toga ataupun bentuk vertikultur, secara mandiri, sedangkan pembelajaran formal ketika guru memasukkan unsur Outdoor Learning Process pada mata pelajaran tertentu (Lynch, 2010).

Berdasarkan survei di Kabupaten Rokan Hulu belum ada sekolah yang disertifikat sebagai sekolah Adiwiyata, yaitu sekolah berbudaya lingkungan. Program Adiwiyata ini memberikan dampak yang baik dalam mewujudkan masyarakat cinta lingkungan. Sekolah Menengah Atas Negeri 2 Rambah Hilir merupakan sekolah yang didirikan atas dasar pertimbangan Bupati Rokan Hulu dalam usaha percepatan peningkatan mutu pendidikan di tingkat SD, SMP, dan SMA, maka perlu dibentuk sekolah berwawasan keunggulan. Berdasarkan rekomendasi Kepala Dinas Pendidikan Kabupaten Rokan Hulu Nomor: 2898/421/2002 tentang pembentukan sekolah berwawasan keunggulan, maka diterbitkan Surat Keputusan Bupati Rokan Hulu Nomor: 86/120/2002 tentang penunjukan dan penetapan SD, SMP dan SMA Berwawasan Keunggulan Kabupaten Rokan Hulu. 
Berkenaan dengan program Adiwiyata, SMA Negeri 2 Rambah Hilir sejak tahun 2010 mulai melaksanakan program Adiwiyata. Pada tahun 2012 SMA Negeri 2 Rambah Hilir ini mendapat penghargaan sebagai sekolah Adiwiyata. SMA Negeri 2 Rambah Hilir masih tetap menjalankan program Adiwiyata, yang dibuktikan dengan program unggulan seperti penghijauan, daur ulang sampah, bank sampah, dan aktivitas 3R (Reuse, Recycling, dan Reduce). Kemajuan yang telah dicapai SMA Negeri 2 Rambah Hilir dalam program Adiwiyata, maka Badan Lingkungan Hidup Kabupaten Rokan Hulu dan Badan Lingkungan Hidup Propinsi Riau memberikan binaan untuk diusulkan menjadi Sekolah Adiwiyata Tingkat Propinsi dan Nasional. SMA Negeri 2 Rambah Hilir merupakan sekolah yang telah mencoba menerapkan program Adiwiyata di tingkat kabupaten, namun masih belum dapat diakui di tingkat provinsi dan nasional. Oleh karena itu, SMA Negeri 2 Rambah Hilir dipilih sebagai mitra agar dapat dilakukan implementasi sekolah Adiwiyata sebagai stimulus sekolah berbasis lingkungan melalui Program Kemitraan Masyarakat Stimulus (PKMS) Sekolah Adiwiyata.

\section{B. METODE PELAKSANAAN}

SMA Negeri 2 Rambah Hilir dipilih menjadi mitra program PKMS Sekolah Adiwiyata dikarenakan:(1) Program di sekolah masih belum mencapai target ditetapkan sebagai sekolah Adiwiyata tingkat provinsi, (2) Kurangnya pembinaan mengenai program Adiwiyata selama 2 tahun terakhir, (3) Pemahaman warga sekolah terhadap program Adiwiyata yang dinilai masih belum baik. Lingkup pemahaman warga sekolah tentang program Adiwiyata mencakup empat aspek yaitu: (a) Pemahaman konsep program Adiwiyata, (b) Komponen-komponen yang termasuk di dalam program Adiwiyata, (c) Tujuan Adiwiyata, dan (d) Prinsip-prinsip program Adiwiyata.

Adapun metode pelaksanan PKMS Adiwiyata SMA N 2 Rambah Hilir agar solusi yang ditawarkan dapat disalurkan dengan baik adalah sebagai berikut:

\section{Analisis Awal}

Pada tahap analisis awal ini ditandai dengan peninjauan permasalahan yang dialami mitra yaitu SMA N 2 Rambah Hilir. Adapun masalah yang dihadapi mitra adalah sebagai berikut:

a. Implementasi program Adiwiyata meski sudah menunjukkan keberhasilannya di tingkat kabupaten, namun harus terus ditingkatkan ke tahap berikutnya, sehingga pada akhirnya menjadi sekolah Adiwiyata Mandiri.

b. Kurangnya pembinaan mengenai program Adiwiyata selama 2 tahun terakhir

c. Pemahaman warga sekolah terhadap program Adiwiyata yang dinilai masih belum baik. 


\section{Proses Persiapan}

Tahap kedua dari pelaksanaan PKMS Adiwiyata SMA N 2 Rambah Hilir adalah proses persiapan yang akan dirancang antara tim pelaksana PKMS beserta mitra. Adapun tahap persiapan meliputi:

a. Peninjauan 4 komponen program dalam pelaksanaa program Adiwiyata yaitu (1) Kebijakan Berwawasan Lingkungan, (2) Pelaksanaan Kurikulum Berbasis Lingkungan, (3) Kegiatan Lingkungan Berbasis Partisipatif, (4) Pengelolaan Sarana Pendukung Ramah Lingkungan.

b. Persiapan Pembinaan Program Adiwiyata

c. Perancangan program unggulan Adiwiyata tambahan

\section{Proses Pelaksanaan}

Tahap ketiga dalam PKMS Adiwiyata SMA N 2 Rambah Hilir adalah proses pelaksanaan. Untuk mencapai tujuan Adiwiyata terdapat 4 komponen program dalam pelaksanaan program Adiwiyata. Keempat komponen tersebut antara lain : (1) Kebijakan Berwawasan Lingkungan, (2) Pelaksanaan Kurikulum Berbasis Lingkungan, (3) Kegiatan Lingkungan Berbasis Partisipatif, (4) Pengelolaan Sarana Pendukung Ramah Lingkungan.

\section{HASIL DAN PEMBAHASAN}

Dalam proses pelaksanaan PKMS ini secara garis besar terbagi menjadi beberapa tahapan yakni:

\section{Sosialisasi PKMS Sekolah Adiwiyata kepada Seluruh Siswa Baru.}

Sosialisasi Adiwiyata dihadiri oleh seluruh siswa baru sebagai upaya pengenalan mengenai Adiwiyata bagi mereka. Kegiatan sosialisasi ini di laksanakan pada tanggal 17 Juli 2019. Sosialisasi mengenai Adiwiyata diberikan oleh Pariang Sonang Siregar, M.Pd sebagai tim penilai dan pembina sekolah Adiwiyata Rokan Hulu.

Program Adiwiyata merupakan bagian dari pendidikan lingkungan hidup yang dilaksanakan berdasarkan prinsip edukatif, partisipatif, dan berkelanjutan. Prinsip edukatif seluruh akademik mendapatakan pengetahuan dan pengalaman dalam program Adiwiyata. Prinsip partisipatif yaitu seluruh komunitas sekolah terlibat dalam manajemen sekolah, yang meliputi keseluruhan proses perencanaaan, pelaksanaan dan evaluasi, sesuai tanggung jawab dan peran. Prinsip berkelanjutan yaitu seluruh kegiatan harus dilakukan secara terencana dan terusmenerus secara komprehensif (Bemawa, 2010). 


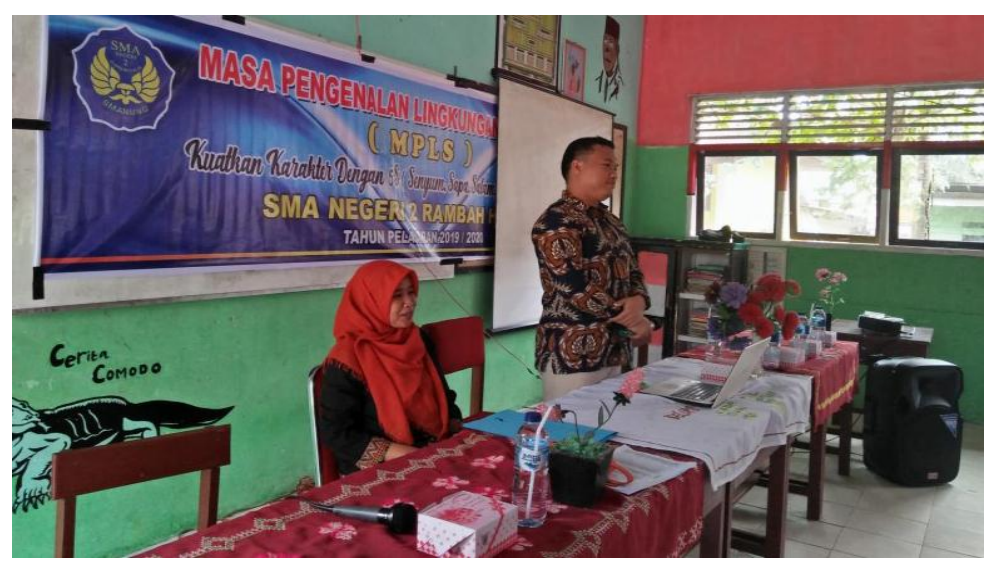

Gambar 1. Penyampaian Materi Seluruh Siswa Baru

\section{Sosialisasi PKMS Sekolah Adiwiyata Kepada Masyarakat Sekolah}

Sosialisasi PKMS sekolah Adiwiyata kepada masyarakat sekolah dihadiri oleh kepala sekolah, majelis guru, tata usaha serta perwakilan siswa setiap kelas. Kegiatan sosialisasi ini di laksanakan pada tanggal 17 Juli 2019. Materi dalam pelaksanaan sosialisasi diberikan oleh 2 orang perwakilan dari Badan Lingkungan Hidup yaitu Elfitri Nawawi, S.Si dan Pariang Sonang Siregar, M.Pd.

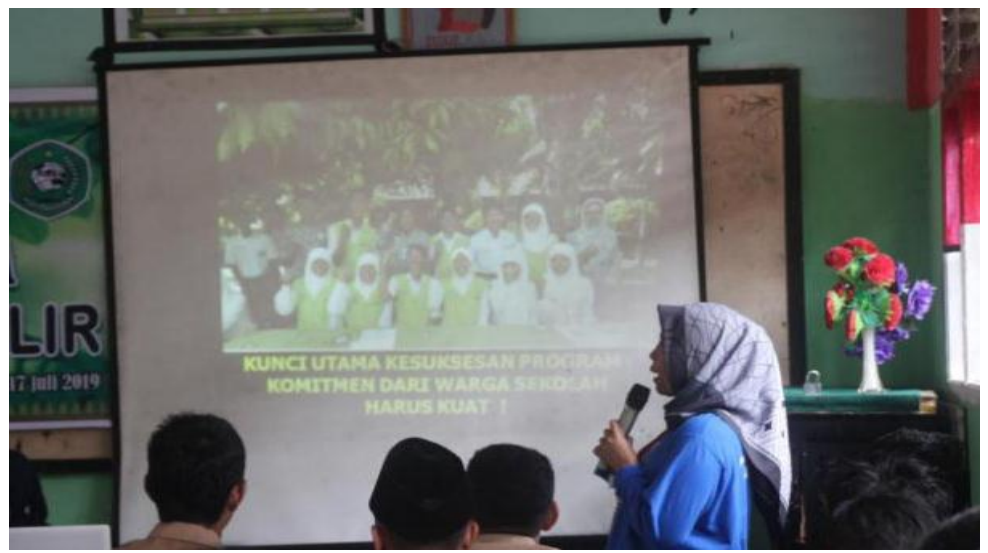

Gambar 2. Penyampaian Materi kepada Masyarakat Sekolah

\section{Pembangunan Green house}

Pembangunan green house sebagai salah satu komponen penunjang dalam penilaian sekolah Adiwiyata telah dilakukan pada tanggal 12-16 Juli 2019. Green house yang dibangun berukuran 9x4 m.

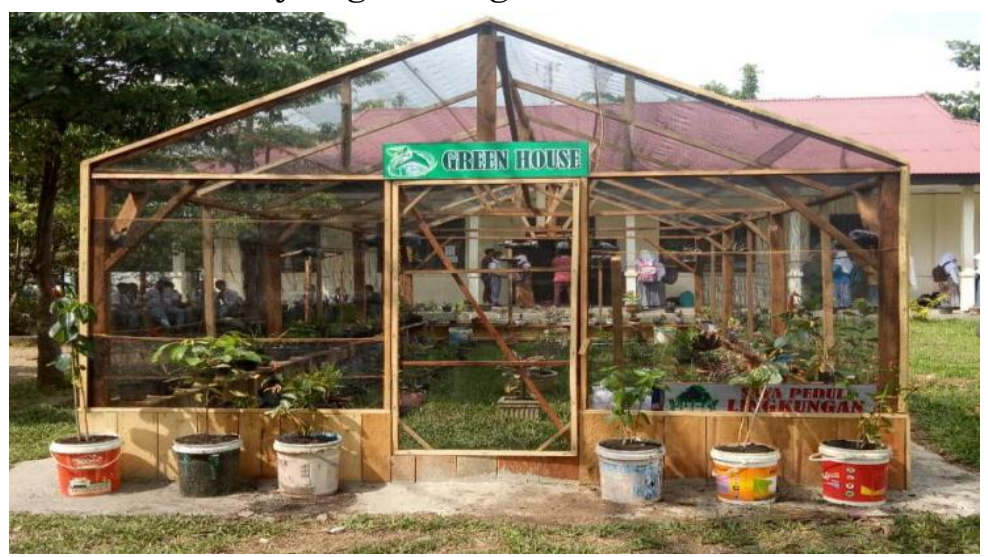

Gambar 3. Hasil Pembangunan Green house 


\section{Pembelian Bibit}

Tim PKMS melakukan pemberian bibit tanaman ke SMA $\mathrm{N} 2$ Rambah Hilir sebgai stimulus agar dapat meingkatkan semangat masyarakat sekolah dalam pengisian green haouse yang telah disediakan.

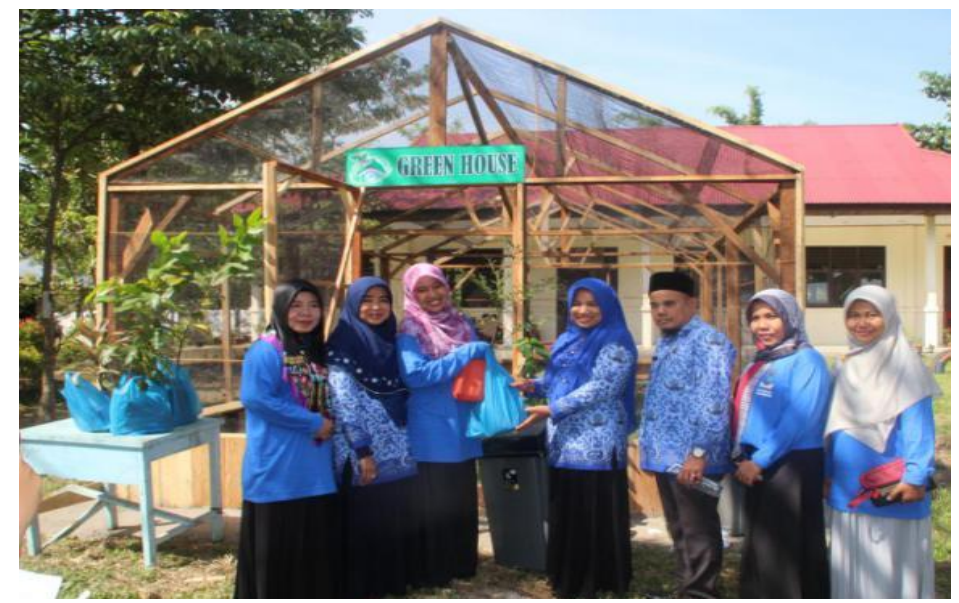

Gambar 4. Penyerahan Bibit Tanaman

Bibit tanaman diserahkan oleh ketua tim PKMS kepada Wakil Kepala Sekolah SMA N 2 Rambah Hilir sebagai bentuk simbol kepedulian lingkungan. Diharapkan bibit yang diserahkan dapat dimanfaatkan dengan sebaiknya.

\section{Pengadaan Tong Sampah dan Slogan Lingkungan}

Tong sampah merupakan salah satu keperluan dalam menjaga kebersihan lingkungan. Oleh karena itu, TIM PKMS memberikan tong sampah kepada SMA N2 Rambah Hilir dalam upaya peningkatan kepedulian lingkungan.
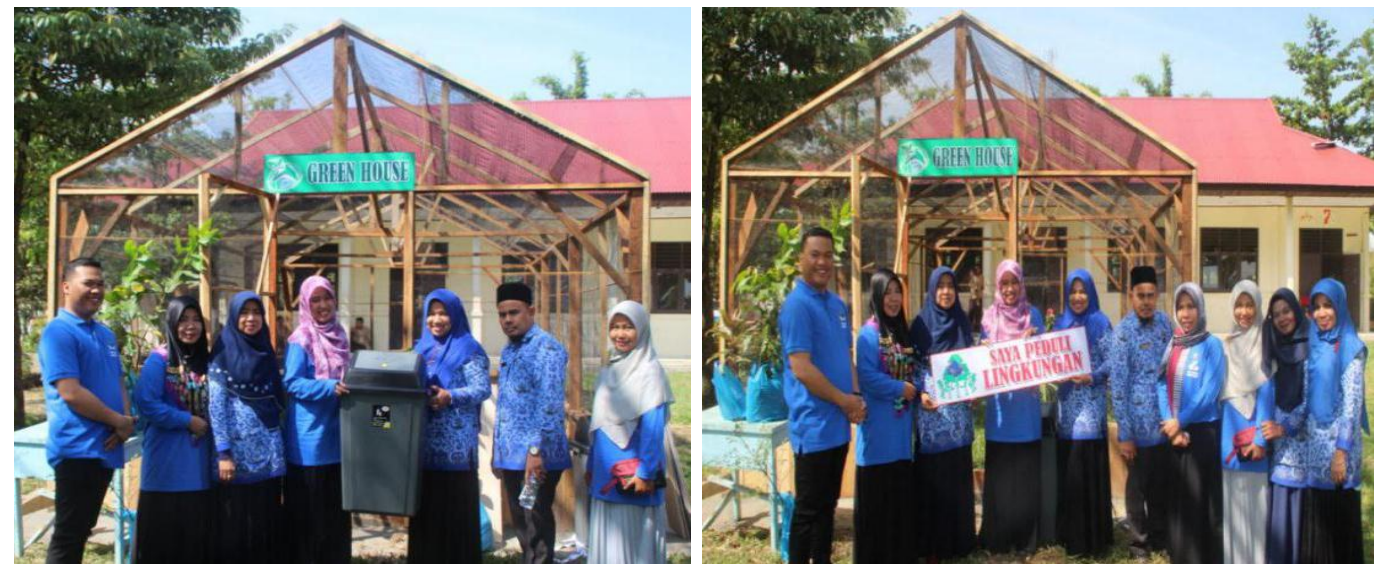

Gambar 5. Penyerahan Tong Sampah dan Slogan Lingkungan

Program Adiwiyata tujuannya adalah membentuk perilaku manusia yang mencintai lingkungannya. Dengan adanya kegiatan Adiwiyata ini diharapkan perubahan prilaku dan sikap dari setiap elemen masyarakat terhadap lingkungan hidup. Kuncinya adalah komitmen setiap elemen sekolah untuk menjalankan program Adiwiyata. 


\section{SIMPULAN DAN SARAN}

Kegiatan implementasi Sekolah Adiwiyata ini, dapat menstimulasi SMA N 2 Rambah Hilir dalam semangat mengembangkan sekolah berbasis lingkungan sebesar $80 \%$. Keberhasilan program ini terlihat dari antusiasnya mitra dalam mengembangkan sekolah Adiwiyata, pembangungan green house, pelestarian TOGA, Slogan lingkungan serta pemberian bibit dan tong sampah. Semoga sekolah di Indonesia mampu menerapkan hasil PKMS ini menuju sekolah peduli lingkungan hidup.

\section{UCAPAN TERIMA KASIH}

Tim penulis mengucapkan terima kasih kepada: (1) DRPM Ristek Dikti RI yang telah mendanai kegiatan pengabdian ini sehingga terlaksana dengan baik; (2) LPPM Universitas Pasir Pengaraian atas dukungannya, dan (3) Mitra PKMS yaitu SMA N 2 Rambah Hilir.

\section{DAFTAR RUJUKAN}

Arba, M. (2013). Konsepsi Perlindungan dan Pengelolaan Lingkungan Hidup Dalam UUPR dan RTRW se Provinsi Nusa Tenggara Barat. Media Hukum, 20(2), 222-250.

Bemawa, H. H. (2010). Implementasi Sekolah Adiwiyata Berbasis Kearifan Lokal. Meneguhkan Peran Penelitian Dan Pengabdian Kepada Masyarakat Dalam Memuliakan Martabat Manusia, (2), 499-510.

Insan, R. K., Nurdin, E. S., \& Darmawan, C. (2018). Pembentukan Kepedulian Lingkungan Smandarikal. Sosietas, 71). https://doi.org/10.17509/sosietas.v7i1.10351

Kasmawati. (2011). Urgensi sumber daya manusia dalam exploitasi sumber daya alam. Jurnal Teknosains, 5, 91-99.

Lynch, J. (2010). Outdoor Learning and Learning Cycles: Moving Forward. Horizons, 43(51), $3-16$.

Paparang, O. E. (2017). Peran Serta Warga Sekolah dalam Melaksanakan Program Adiwiyata Di Sma Negeri 9 Lempake Samarinda. eJournal Administrasi Negara, 5(2), $5922-5933$.

Rotari, S. (2017). Peran Program Adiwiyata Mandiri dalam Meningkatkan Kepedulian Lingkungan Peserta Didik. Citizenship Jurnal Pancasila Dan Kewarganegaraan, 5(1), 42. https://doi.org/10.25273/citizenship.v5i1.1177

Selinaswati, S. (2019). Sinergisitas Pendidikan Karakter dan Sekolah Adiwiyata. ABDI: Jurnal Pengabdian Dan Pemberdayaan Masyarakat, 1(1), 21-27. https://doi.org/10.24036/abdi/vol1-iss1/4 